\title{
Redes sociales y nuevas tecnologías
}

\section{Social networks and new technologies}

EDITORIAL

\section{Cecilia Ugalde}

\author{
Escuela de Comunicación \\ Universidad del Azuay \\ cugalde@uazuay.edu.ec \\ orcid.org/0000-0001-7716-6023
}

\section{Resumen:}

Las redes sociales y nuevas tecnologías de la comunicación influyen cada vez más en distintos aspectos de nuestras vidas, y moldean la forma en la que nos relacionamos, aprendemos y expresamos. Necesitamos contextualizar los fenómenos mediáticos en función del entorno en el que se desempeñan, ya que su aplicación da resultados diferentes en lugares diversos, por ser culturalmente sensibles.

\section{PALABRAS CLAVE}

Redes sociales, Nuevas tecnologías, Investigación, TIC.

\section{Abstract:}

Social networks and new communication technologies increasingly influence different aspects of our lives. They shape the way we interact, learn and express ourselves. There is a need to contextualize the media phenomena according to the environment in which they work, since their application gives different results in different places because they are culturally sensitive.

\section{KEYWORDS}

Social networks, New technologies, Research, ICT. 
Las redes sociales y nuevas tecnologías de la comunicación se han constituido como parte del accionar social global, en el que participan muchos actores, desde los ciudadanos comunes, hasta activistas, organizaciones no gubernamentales, medios de comunicación, gobiernos, etc. (Shirky, 2011); estas se han introducido en nuestras vidas y han modificado nuestros hábitos de consumo mediático e interacción social, dando nueva forma a la comunicación como la conocíamos, hasta llegar a lo que se define como masspersonal communication, ese concepto que fusiona la comunicación masiva con la interpersonal (O'Sullivan y Carr, 2018).

Cada día cobra más fuerza la influencia que estas nuevas tecnologías tienen en nuestras vidas, dando grandes pasos desde aquellos primeros estudios sobre el moldeado social de la tecnología al que MacKenzie y Wajcman (1999) hicieron referencia el milenio pasado. Estas tecnologías se han inventado, diseñado e implementado para uso de las personas en contextos sociales particulares (Graham \& Dutton, 2019). Además, las nuevas tecnologías y redes sociales ofrecen a las organizaciones la posibilidad de acceder a flujos de información que pueden llevar a la introducción de cambios en sus sistemas de administración del conocimiento, lo que, a su vez, puede ocasionar mejoras en su rendimiento (Nisar, Prabhakar, y Strakova, 2019); aunque también existen retos y amenazas que se deben considerar más allá de las oportunidades que evidentemente se presentan, por lo que se sugiere considerar axiomas como los propuestos por Berthon Pitt, Plangger y Shapiro (2012):

(1) las redes sociales son siempre una función de la tecnología, la cultura y el gobierno de un país o contexto en particular; (2) los eventos locales rara vez siguen siendo locales; (3) los eventos globales probablemente se (re) inter- preten localmente; (4) las acciones y creaciones de los consumidores también dependen de la tecnología, la cultura y el gobierno; y (5) la tecnología es históricamente dependiente. ( $p$. 261)

Así pues, es necesario contextualizar los fenómenos mediáticos y tener clara la realidad de cada entorno en el que se desempeñan, lo que nutre y da riqueza al fenómeno comunicacional que no se comporta de igual manera en realidades distintas, lo que abre un sinnúmero de posibilidades científicas a explorar.

Se ha enfatizado mucho en los poderosos efectos que las redes sociales pueden tener en las distintas maneras en las que las organizaciones se conectan con sus clientes y stakeholders externos, en muchas áreas del marketing y gerencia de la relación con los clientes (Leonardi, Huysman, y Steinfield, 2013). Este monográfico de Obra Digital, "Redes sociales y nuevas tecnologías en líneas multidisciplinarias", correspondiente a los meses de septiembre 2019, enero 2020, pretende a través de seis artículos, mostrar algunos aspectos de las implicaciones que los medios digitales tienen en ámbitos tan diversos como el de las federaciones nacionales de fútbol, la política andaluza o ecuatoriana, el video participativo y la alfabetización visual, el influencer literario, o la internacionalización universitaria; y permite vislumbrar cómo la sociedad, los medios y la educación se adaptan a los retos que las redes sociales y nuevas tecnologías presentan.

Investigadores de varias latitudes presentan en este número 17 resultados empíricos basados en un soporte teórico que permiten visualizar cómo los avances tecnológicos dan forma e impactan las relaciones políticas, sociales y culturales. No se pretende realizar generalizacio- 
nes, sino más bien presentar distintas perspectivas en entornos y con tecnologías específicas.

Sabemos que las redes sociales y nuevas tecnologías de la comunicación seguirán afectando nuestro día a día y aquel de las empresas e instituciones que las utilizan, por lo que estamos seguros de que esta temática continuará cobrando importancia y ganando espacio en el debate público, académico y científico.

La publicidad en la prensa escrita y el consumo mediático por parte de los millennials conforman nuestra sección miscelánea y completan este número diecisiete que por primera vez se publica íntegramente en español e inglés.

\section{Referencias}

Berthon, P. R., Pitt, L. F., Plangger, K., \& Shapiro, D. (2012). Marketing meets Web 2.0, social media, and creative consumers: Implications for international marketing strategy. Business horizons, 55(3), 261-271. doi: 10.1016/j.bushor.2012.01.007

Graham, M., \& Dutton, W. H. (Eds.). (2019). Society and the internet: How networks of infor- mation and communication are changing our lives. Oxford University Press.

Leonardi, P. M., Huysman, M., \& Steinfield, C. (2013). Enterprise social media: Definition, history, and prospects for the study of social technologies in organizations. Journal of Computer-Mediated Communication, 19(1), 1-19. doi: 10.1111/jcc4.12029

MacKenzie, D., \& Wajcman, J. (1999). The social shaping of technology. Open university press.

Nisar, T. M., Prabhakar, G., \& Strakova, L. (2019). Social media information benefits, knowledge management and smart organizations. Journal of Business Research, 94, 264-272.

O'Sullivan, P. B., \& Carr, C. T. (2018). Masspersonal communication: A model bridging the mass-interpersonal divide. New Media \& Society, 20(3), 1161-1180. doi: $10.1177 / 1461444816686104$

Shirky, C. (2011). The political power of social media: Technology, the public sphere, and political change. Foreign affairs, 28-41. 